outcome. However there are concerns whether preterms accumulate excess fat during NICU stay.

Aim Aim of this study was to compare skinfold thickness of preterms when they reached 35 weeks corrected age (CA) with that of 35 week born controls.

Methods Appropriate for gestational age (AGA) preterms born $\leq 32$ weeks gestational age (GA) had skinfold thickness measured from 5 body sites by using Holtain caliper at 35 weeks CA as well as weight, length, head circumference (HC) and ponderal index (PI), results were compared with gender matched AGA near term controls born at 35 weeks gestation with nonparametric tests. Data are expressed as median and range.

Results 26 preterms (10 males GA:30.5 w (28-31), BW: 1500g (1040-1700)), 16 females GA:29 w (25-32), BW: 985g (610-1800)) were compared to 20 controls (10 males BW:2175g (1837-2356), 10 females BW: 2115g (1815-2362)).Skinfold thickness measured from triceps, biceps, subscapular, suprailiac and midtigh regions were significantly higher in patients compared to controls both in girls and boys (Figure 1.2). However weight, length, HC and PI were similar.

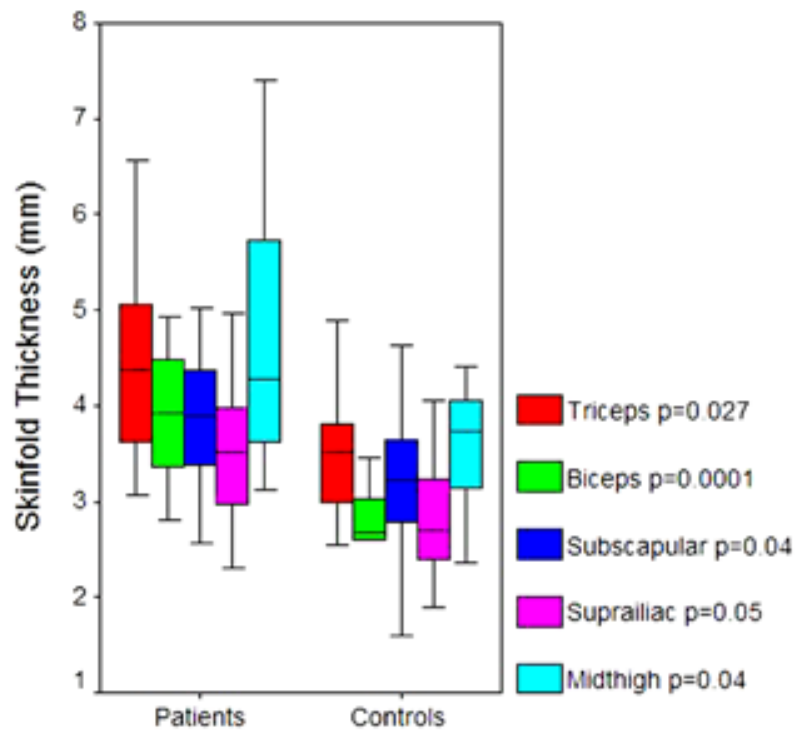

GIRLS

Abstract 340 Figure 1 Girls

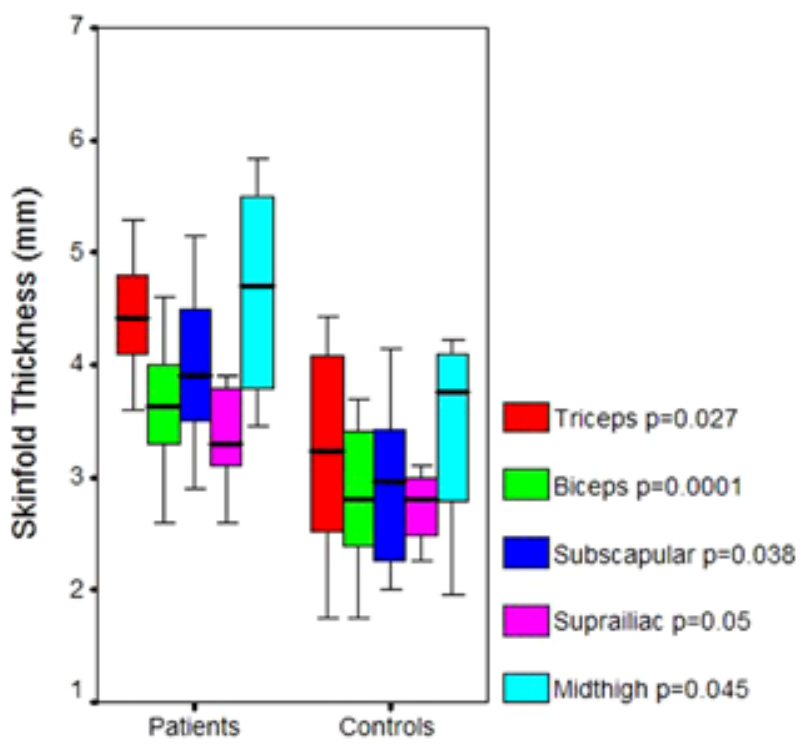

Abstract 340 Figure 2 Boys
Conclusion Enriched feeding with increased protein and calories is essential for preterms during NICU stay however the way we do it does not seem to lead to in utero body composition which is considered ideal.

\section{CHOLESTEROL BIOSYNTHESIS IN PRETERM INFANTS ON PARENTERAL NUTRITION WITH A LIPID EMULSION CONTAINING 10\% FISH OIL (FO): A PILOT STUDY}

doi:10.1136/archdischild-2012-302724.0341

${ }^{1}$ C Biagetti, 'L Vedovelli, 'S Savini, 'R D'Ascenzo, 'I Burattini, 'MP Bellagamba, ${ }^{2}$ PE Cogo, 'VP Carnielli. 'Division of Neonatology, Polytechnic University of Marche, Ancona; ${ }^{2}$ Pediatric Cardiac Anesthesia/Intensive Care Unit, Department of Pediatric Cardiology and Cardiac Surgery, Bambino Gesù Children's Hospital, Roma, Italy

Background and Aims Limited data are available on the metabolic effects of intravenous fish oil (FO) in premature infant. We reported on the plasma cholesterol lowering effect of an intravenous lipid emulsion containing $10 \%$ FO or FMS (10\% FO, $50 \%$ MCT, 40\% soybean oil-SO) when compared with MS $50 \%$ MCT, $50 \%$ SO) (D'Ascenzo et al. JPediatr 2011). Aim of this study was to ascertain if the lower plasma cholesterol concentrations resulted from reduced biosynthesis or enhanced clearance.

Methods Eighteen premature infants were randomised to receive FMS (n=9, GA 199 \pm 17 days, BW 983 \pm 138 g) or MS (n=9, GA 202 \pm 17 days, BW $992 \pm 178 \mathrm{~g}$ ). The IV lipids were increased to $2.5 \mathrm{~g} \cdot \mathrm{kg}^{-1} \cdot \mathrm{d}^{-1}$ in the first week of life. On day 7 patients received an oral dose of deuterated water for the measurement of cholesterol and palmitate biosynthesis. The incorporation of deuterium from water into cholesterol (cholesterol biosynthesis) was measured by Gas Chromatography and Combustion Isotope Ratio Mass Spectrometry (GC-C-IRMS). Fractional and Absolute Synthesis Rates (ASR) were obtained and compared by Mann-Whitney Test.

Results Plasma free cholesterol concentrations were significantly lower in FMS than in MS ( $53 \pm 5$ vs $64 \pm 9 \mathrm{mg} / \mathrm{dl}, \mathrm{p}=0.01)$. ASR were $8.5 \pm 3.4 \mathrm{vs} 8.4 \pm 2.6 \mathrm{mg} / \mathrm{kg} / \mathrm{d}$ in FMS and MS respectively ( $\mathrm{p}=0.93$ ).

Conclusions Intravenous $\mathrm{FO}$ in preterm infants has marked cholesterol lowering effect but cholesterol biosynthesis was not reduced. Measurements of cholesterol catabolism are in progress.

\section{MATERNAL PREDICTORS OF HUMAN MILK INTAKE IN EXTREMELY PRETERM INFANTS}

doi:10.1136/archdischild-2012-302724.0342

'S Omarsdottir, ${ }^{2} \mathrm{~A}$ Adling, 'L Legnevall, ${ }^{3} \mathrm{AK}$ Edstedt Bonamy, 'M Vanpée. ${ }^{1}$ Neonatal Unit, Karolinska University Hospital; ${ }^{2}$ Karolinska Institute; ${ }^{3}$ Neonatal Unit, Stockholm South General Hospital, Karolinska Institute, Stockholm, Sweden

Background and Aims Mother's own breast milk (MBM) is the most advantageous enteral food for extremely preterm infants (EPIs). Mothers of EPIs are at risk for inadequate expression of breast milk but determinants of MBM production are not well identified. The aim of the study was to investigate maternal predictors for $\mathrm{MBM}$ intake in EPIs during the neonatal period and at discharge.

Methods The sample consisted of 109 mothers and their 117 EPIs born at Karolinska University Hospital from 2005-2009. Maternal data was retrieved from prenatal and obstetrical medical charts. In infants, birth data and information on enteral intake was collected from neonatal charts during the first 6 weeks of life and at discharge.

Results Mean maternal age was 31.3 years. Mean infant gestational age and birth weight were $26+0$ weeks and 850 grams. Only mothers with high MBM production at 3 weeks (MBM $>90 \%$ of total enteral food intake) maintained their lactation over time. Predictors of low neonatal MBM production were unemployment, use of nicotine, low educational level, non-Swedish origin, non-cohabiting status 